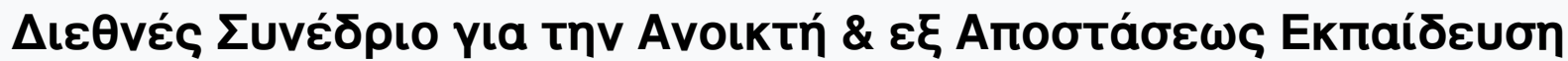

Tón. 8, Ap. 4B (2015)

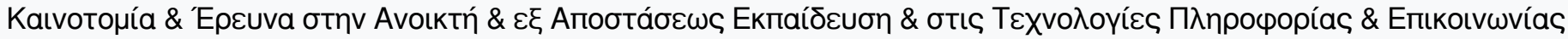

| Пракuiká

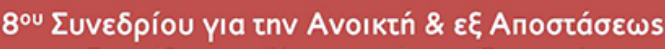

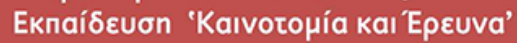

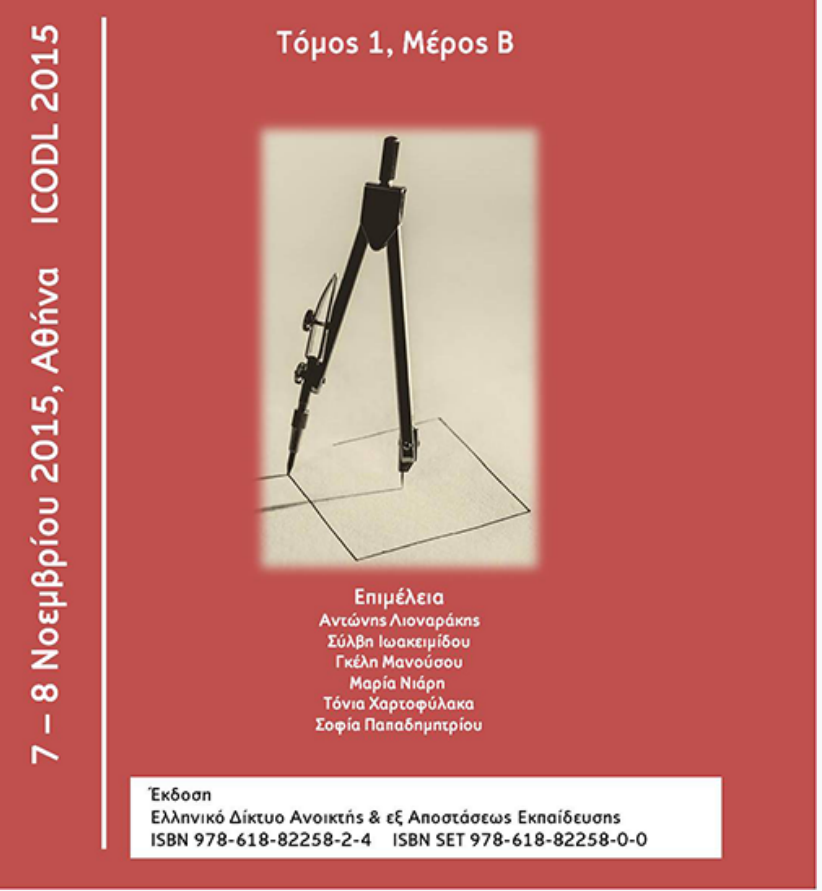

Teaching an Applied Art through Distance Learning: The case of Lighting Design

Nikolaos Trivyzadakis

doi: $10.12681 /$ icodl. 58 


\title{
Teaching an Applied Art through Distance Learning: The case of Lighting Design
}

\author{
Nikolaos Trivyzadakis \\ Professor \\ Hellenic Open University \\ School of Applied Arts, Adjunct Faculty Member \\ nikolaostrivyzadakis@gmail.com
}

\begin{abstract}
There are several difficulties and obstacles concerning the instruction of an Applied Art discipline through Distance and Online learning only. An example of that is the case of Lighting Design. A complete analysis of the substantial elements of that discipline shows its two-fold character based both on artistic/theoretical and scientific/technical premises. While Distance and Online learning methods are adequate for the teaching of the artistic/theoretical part of Lighting Design, the technical/scientific one demands also face to face sessions, outdoor activities and laboratory experimentation, a condition that will assure the tangible contact of the students with the practical nature of the activity. The same scenario seems to characterize all Applied Arts in the cases where an academic institution of higher education wishes to organize a program for their proper academic teaching. Taking that as example, we could generalize by suggesting that the appropriate way to construct an academic program for an Applied Art should be based on blended learning with the obligatory combination of Distance and Online learning methods on the one hand and face to face sessions and activities on the other.
\end{abstract}

Key-words: Applied Arts, Lighting Design, Blended learning

\section{Introduction}

The presence of Distance Learning programs within institutions of higher education seems to be for the last decades not only an educational privilege but also a social necessity (Holmberg, 2003; Pange et al., 2011). Nonetheless, various and important questions and doubts rise concerning the appropriateness of all disciplines and scientific fields for instruction through Distance and Online Learning methods and practices (Bell, Federman, 2013). There are not few that claim that fields containing technical knowledge and practice should only be instructed within the limits of a classroom or a laboratory. One such field that needs special treatment is the discipline of Lighting Design that "seems" to search its position between Distance and Face to Face Learning. Unavoidably, the effort to specify how such a discipline should be instructed through an academic program of higher education should begin from its deconstruction to its particular components.

\section{Lighting Design: An Applied Art}

After centuries of philosophical evolution and mental processes, human thinking and practice ended up at approaching artistic production through the system of Fine Arts, the core of which is painting, sculpture, architecture, poetry and music (Kristeller, 
1951). The special trait of Fine Arts is that they produce objects or actions, material or spiritual, which are about something (an idea) that is incorporated in their being (Danto, 2000). Fine Arts refer only to themselves and they complete their creation in their own existence (Trivyzadakis, 2013). Taking the background of Fine Arts for granted, a new category of artistic production made its appearance during the 18th century. The innovation of that new kind of Art was that its products should also have, apart from their pure artistic content, specific practicalities for the life of man. In that way, Art could be a more vivid and vital part of human society, by which all people could benefit. In that frame, the social and philosophical motion from pure to practical Art made possible the autonomous recognition of Applied Arts (Pov́ $\pi \alpha, 2003)$.

On the other hand, Lighting Design came from the inherent and ever-lasting tendency of human beings to illuminate their surroundings. The act of illumination aims exactly at making visible and therefore editable and useful everything that lies in physical darkness (Design Museum, 2010). In that way, humans were in position to build closed spaces and constructions for their living, working and praying (rituals), while the dark hours of the night couldn't suspend their activities (Mov $\lambda \lambda$ ov́, 2011;

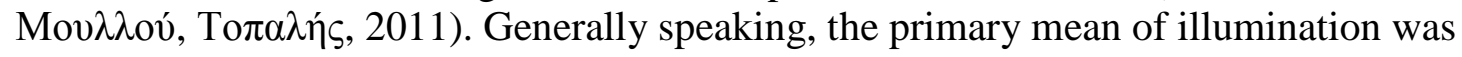
fire based candles, torches, hearths and lanterns, which were succeeded after many centuries by luminaries and lambs powered by electricity. In any case, the characteristic that marks the path from simple illumination to Lighting Design is the surpassing of visibility for the creation of certain visual effects and experiences (Beforelight, 2011). That could lead to a definition of Lighting Design as the organized and systematic attempt to manipulate the productive effect of lighting sources in order to produce visual experiences that are expressive and sensuous. Some indicative applications of Lighting Design are architectural lighting, indoor and outdoor lighting, theatrical lighting, photography and cinema lighting and lighting for monuments of cultural heritage or museums. Special reference should be given to the capacity of a Lighting Designer to design and create luminaries according to prospective needs (Kelly, 1952).

The detail that can offer the expressive and sensuous content to the visual experience created by the manipulation of light is the application of artistic content that derives from Fine Arts. That heads us to the conclusion that while all people are potential illuminators, Lighting Designers are the individuals who are capable of benefiting from the content of Fine Arts in order to manipulate light as a tool for the production of universal expressive and sensuous visual compositions. The Lighting Designer doesn't only illuminate an object or scenery but also he tries to extract a new truth from it, to give birth to a new "lighting being" (Yot, 2011). It becomes clear that while illumination is a simple act of daily life, Lighting Design belongs to the class of Applied Arts.

In addition, modern Lighting Design has also a scientific - technical dimension. This is consequence of the constant evolutions in the field of light science and technology. The developments in the science of Physics offered the analysis of light as a natural phenomenon, while technical experiments and laboratory results created evolved lighting technologies such as LED, OLED or laser luminaries. We should not forget that modern software applications, such as Photoshop, Relux or Dialux gave the opportunity for the creation of digital but exact representations of lighting effects based on the dynamic of multimedia achievements. Finally, we should also refer to the need for compromise with the legislation concerning consumption and ecological affairs or lighting pollution (Cuttle, 2003). 
After the above analysis, it became evident that Lighting Design is a two - fold Applied Art that includes two successive stages. The primary is the creative synthetic stage where the Designer maps a lighting frame based on the formation of an expressive visual experience by the use of visual perception and the Fine Arts background. Consequently, the second stage demands multimedia reconstruction and technical experimentation in order to give material and applied visual existence to the lighting idea of the first stage, combining use of available lighting technologies and compliance to current lighting legislation.

\section{Teaching Lighting Design: Aims and methods}

The two - fold character of Lighting Design should be the guiding idea behind the strategic formation of an educational program of higher education concerning its instruction as Applied Art and Science. Regardless the methods to be followed and the special needs to be satisfied, the general aims of an academic program that seeks to provide a complete package of educational experience for potential Lighting Designers should be:

1) Field of Knowledge. Students should be acquainted with:

1.1. Aesthetic and artistic trends, especially those concerning visual arts. The contact with art should not be confined only to Art history and philosophy, but emphasize on the interaction between art and visual perception.

1.2. Current multimedia and software applications concerning Lighting Design.

1.3. The methods to approach and analyze Light according to the achievements of the Science of Physics.

1.4. Technical matters about light technologies like types of lamps and luminaries.

1.5. Legislation about light pollution and ecology matters.

2. Field of Skills. Students should acquire the capacities to:

2.1. Combine both aesthetic and technical/scientific elements when processing a lighting idea in order to create a lighting synthesis.

2.2. Produce through a creative manipulation of Light visual experiences based on the exploitation of the dynamics of visual perception and its impact on human conscience.

2.3. Compose complete and realistic lighting studies.

2.4. Supervise lighting projects.

3. Field of Habits of Mind: Students would be in position to:

3.1. Understand and conquer the two-fold character of Lightning Design.

3.2. Cultivate their imagination and evolve their thinking in various ways concerning the approach of light impact in modern daily life.

3.3. Overcome the simple use of Light as a factor of visibility and realize its potentiality to create lighting and visual beings.

The above mentioned aims could be achieved through a multidimensional instruction that involves:

1. A theoretical part with courses concerning Art history and philosophy, visual perception, software and multimedia, legislation and Physics.

2. A technical part that involves experimental contact with light technologies and luminaries. The use of an organized laboratory is crucial for the success of that part.

3. An "outdoor" part, which would assure the contact of students with actual light artists and professionals during their work. Proposed activities are visits to theaters or to technical services of public or private sector that realize light projects. 


\section{Teaching Lighting Design through Distance and Online learning}

The organization of an appropriate educational program for Lighting Design through Distance Learning could be possible only if it could be compatible with the above mentioned goals concerning Lighting Design as Applied Art. In any case, we should bear in mind that a Lighting Design program should be based on a multidimensional teaching with a theoretical, a technical and an outdoor part.

In that frame, a Distance and Online learning Lighting Design program could benefit from the advancements of the current information and communication technologies in order to offer a suitable educational environment for the teaching of all potential dimensions and folds that are related with the artistic character of the discipline. Under that angle, the program could offer electronic texts and handbooks (pdf or word files), audiovisual content (mp3 files, digital videos, seminars, and lectures), training material (case studies, evaluation of lighting applications, encouragement of proposition of new ideas) and most of all interactive capacities based on live and oral communication between the educators and the adult learners (teleconferences). In such a way, the students of the program could acquire consciousness of the multidimensional character of Lighting Design, which, through the program, could be approached both in its artistic and scientific parameters. Students coming in contact with the artistic and visually perceptive atmosphere around the use and manipulation of Light would be offered the necessary and appropriate cognitive background from the science of Physics in order to analyze and use Light as natural or artificial phenomenon. With that background, the students may acquire the capacity to proceed to illumination synthesis taking under consideration additional parameters as lighting legislation, pollution and power efficiency. A great help for the students could become the teaching of multimedia and software applications through which an accurate visualization of the each lighting project is possible and feasible. It seems that a program, based exclusively on Distance and Online learning methods could reach completely the goals concerning the theoretical part.

On the other hand, it seems that a solely Distance and Online learning program could never ensure a contact of the students with the practical dimension of Lighting Design. In that frame, the program by nature could not involve any practical experimentation with Lighting technologies or physical luminaries. Furthermore, no Lighting Laboratory could be organized because its existence presupposes the physical presence of the students. Therefore, the students will not have the opportunity to practically test and evolve the theoretical background that the program could offer. It is then up to them, according to their own initiatives and accesses to try and acquire a more practical part of Lighting education, which in any case couldn't be a substantial part of the Distance learning program.

The same condition concerns also the necessary outdoor part. Since the program would be offered through Distance Learning, no educational visits to Lighting professionals could be arranged. If doing so, the program would endanger to create unequal terms for the students, while violating the Distance Learning character of the academic structure. Nonetheless, in that way the program seems to condemn itself to be isolated to a total academic level, losing any potential for communication and contact with the real professional life of Lighting Designers.

\section{Conclusion}

After the above analysis, it became clear that Lighting Design could be treated as an example of the difficulties concerning an Applied Art that needs to be instructed through a Distance Learning institution. Applied Arts are occupations of the human 
creativity that involve both an artistic and a technical-scientific dimension. The artistic premises become easily part of an educational program offered through Distance and Online learning. The existing educational technological means are more that adequate to ensure that the students receive all necessary background. The same condition is also applied as far as the theoretical fold of the technical - scientific dimension is concerned. That is not the case though with the practical part of the technical-scientific dimension. A program without obligatory face to face sessions, organized visits to professional applied artists or relative institutions of both private and public sector and generally without physical contact with the practical object of the Applied Art lacks experimentation and material application and thus offers an "incomplete" educational experience. That leads us to the conclusion that blended learning seems to be the ideal way to transmit knowledge, skills and habits of mind in the academic cases where a theoretical and an applied dimension are substantial parts of the scientific field to be instructed.

\section{References}

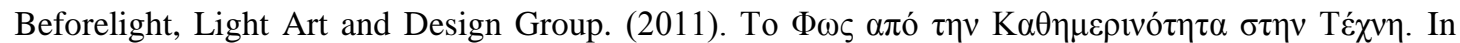

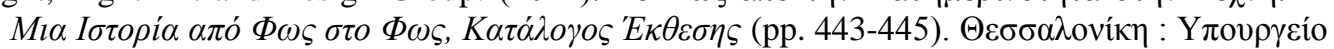

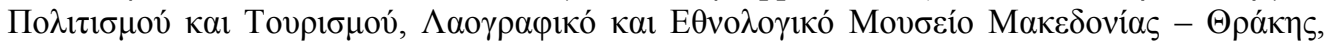

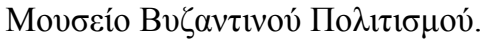

Bell, B. Federman, J. (2013). E-Learning in Postsecondary Education. The Future of Children, 23(1), 165-185.

Cuttle, C. (2003). Lighting by Design. Oxford, Amsterdam, Boston, London, New York, Paris, San Diego, San Francisko, Singapore, Sydney, Tokyo: Architectural Press.

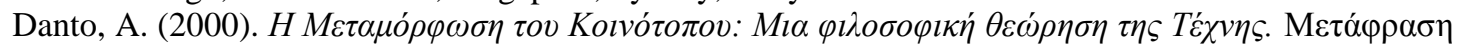

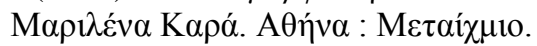

Design Museum. (2010). How to Design a Light. London : Conran Octopus Ltd.

Holmberg, B. (2003). Distance Education in Essence. An overview of Theory and Practice in the Early Twenty First Century. Oldenburg : Bibliotheks- und Informationssystem der Carl von Ossietzky Universität Oldenburg(BIS) - Verlag.

Kelly, R. (1952). Lighting as an Integral Part of Architecture. College Art Journal, 12(1), 24-30.

Kristeller, P.O. (1951). The Modern System of Arts: A Study in the History of Aesthetics Part I. Journal of the History of Ideas, 12(4), 496-527.

Pange, J. Toki, E. Lekka, A. Distance Learning: A myth or a necessity for educators? In Iadis International Conference on International Higher Education (IHE 2011), 8 to 10 December 2011 (pp. 80-84). Shanghai: International Association for Development of the Information Society.

Trivyzadakis, N. (2013). Approaching Art in Distance Learning: The necessity of oral interaction. In

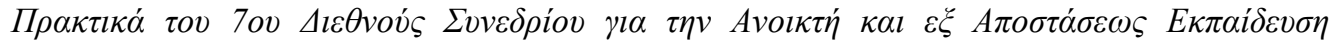

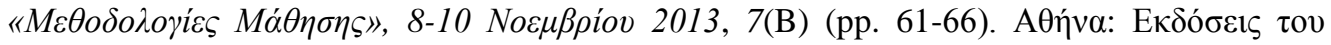

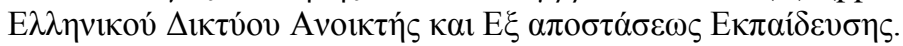

Yot, Richard. (2011). Light for Visual Artists. Understanding \& Using Light in Art \& Design. London : Laurence King Publishing.

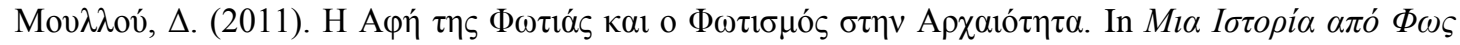

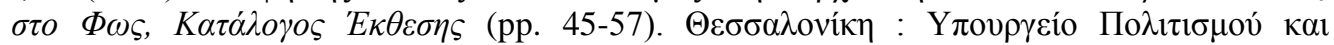

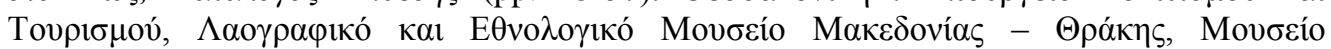

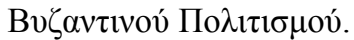

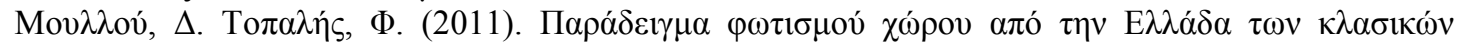

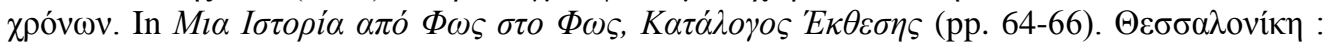

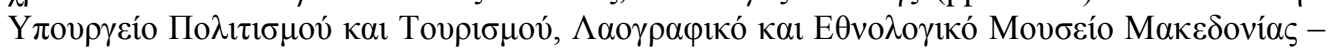

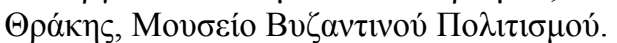

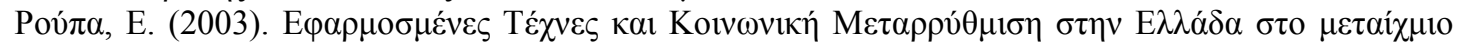

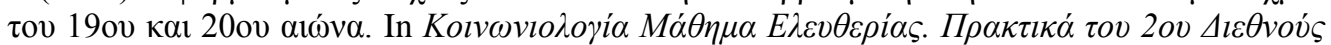

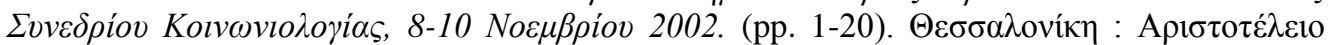

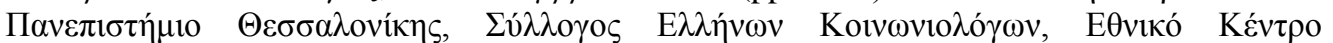

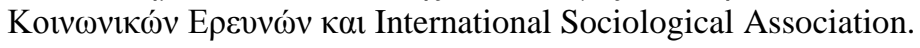

